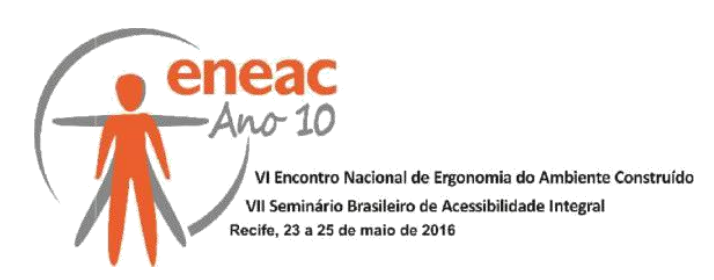

\title{
BOATE KISS: DEFINIÇÃO DE UM MÉTODO PARA AVALIAÇÃO DA PERCEPÇÃO DO AMBIENTE DA TRAGÉDIA.
}

\section{BOATE KISS: definition of a method to evaluate the perception of the tragedy's environment.}

\author{
BRONDANI, Sergio Antonio (1); \\ PRADO, Ana Lúcia Cervi (2); \\ S ANTOS, Maike Adriel dos (3);
}

(1) Universidade Federal de Santa Maria, Doutor

e-mail: serbrondani@gmail.com

(2) Universidade Federal de Santa Maria, Doutora e-mail: a.lucia@terra.com.br

(3) Universidade Federal de Santa Maria, Acadêmico de Desenho Industrial

e-mail: maikeadriel@gmail.com

\begin{abstract}
RESUMO
A pesquisa apresenta um método de avaliação da percepção que será utilizado por parte dos usuários que frequentaram o ambiente no dia da tragédia. Seu principal objetivo é avaliar a eficiência da sinalização de emergência e segurança, considerando as recomendações das normas nacionais vigentes. Em relação ao proposto, a pesquisa é classificada como explora tória, tendo no seu processo a utilização de Mapas Mentais como ferramenta para a busca de informações/elementos que irão auxiliar nas análises e interpretações futuras. As inúmeras variáveis consideradas no estudo proporcionaram a criação de um protocolo básico que serviu de roteiro para as entrevistas e representações, considerado premissa para validação do processo.
\end{abstract}

Palavras chave: Boate Kiss; percepção ambiental; Mapa Mental.

\begin{abstract}
The research presents a method for assessing the perception that will be applied by part of the users who attended the atmosphere on the day of the tragedy. Its main objective is to assess the hazard warning efficiency and security, considering the recommendations of current national standards. The proposed research is classified a s exploratory, using Mind Maps as a tool for finding information / elements that will assist in future analyzes and interpretations. The numerous var iables considered in the study led to the creation of a basic protocol that served as a roadmap for interviews and representations, considered premise for process validation.
\end{abstract}

Keywords: Boate Kiss; environmental awareness; Mental map. 


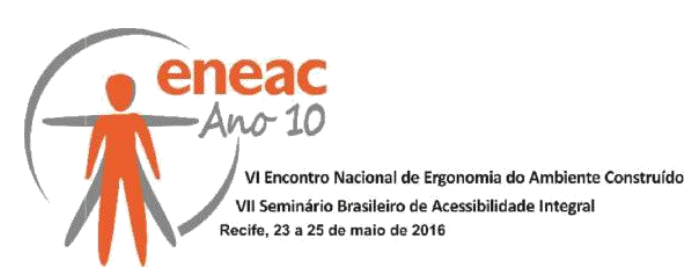

\section{INTRODUÇÃO}

Em 27 de janeiro de 2013, aproximadamente às 03:00 horas, a cidade de Santa Maria, no Rio Grande do Sul, é acordada com a trágica notícia de um incêndio na Boate Kiss, de resultados catastróficos e que entraria para a história e estatísticas com o um dos maiores acidentes mundiais. Resultou do acontecimento, um saldo de 242 mortos e centenas de sobreviventes com sequelas de toda ordem. O público em sua maioria era composto de pessoas jovens.

Figura 1: vista externa caracterizando a via pública e o acesso da Boate Kiss.

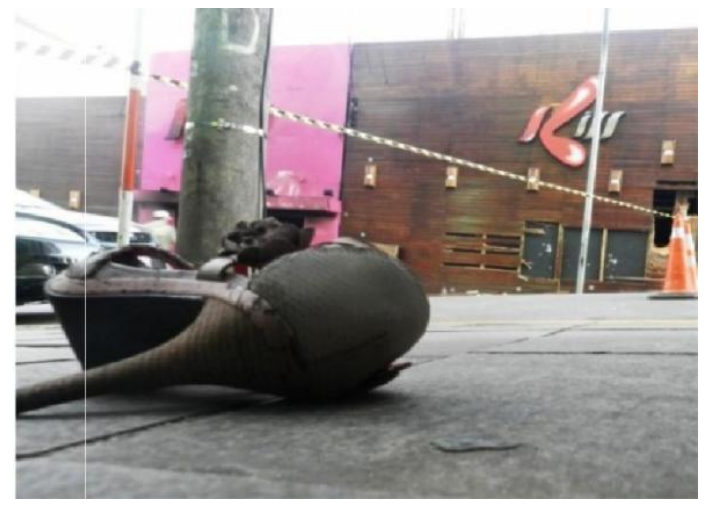

Fonte: Google Imagens

As condições de conforto e segurança no uso dos ambientes projeta dos, especialmente onde ocorrem aglomerações de pessoas, normalmente são condicionado s à observação de leis e normas que tratam do assunto. Este fato pode ser hoje verificado na maioria dos países, resultados de acontecimentos como é o caso da Boate Kiss e que servem de exemplo para evitar futuros acidentes com esta semelhança. Diante desta constatação, podemos nos perguntar: porque então continua a acontecer este tipo de acidente? Algumas situações similares ao caso da Kiss são facilmente verificadas, algumas com datas anteriores e outras posteriores a data da tragédia. Não vamos neste relato julgar os acontecimentos, vamos sim observar e registrar os elementos que colaboraram para 0 fato. Contextualizar um breve histórico recente de tragédias similares é importante para o entendimento do conteúdo a ser pesquisado:

- Data 21/02/2003: Station Nightclub, West Warwick, RI, USA. Incêndio: ignição por fogos de artifício da banda. 100 mortos ;

- Data 30/12/2004: República de Cromagnón, Buenos Aires, Argentina. Incêndio: ignição por fogos de artifício da banda. 194 mortos;

- Data 27/01/2013: Boate Kis s, Município de Santa Maria/RS, Brasil. Incêndio: ignição por fogos de artifício da banda. 242 mortos;

- Data 30/10/2015: Club Colectiv, Bucareste, Romênia. Incêndio: iniciado após uma explosão durante um espetáculo pirotécnico. 32 mortos.

Facilmente podemos observar que nos casos acima citados, todos relatam ações semelhantes que deram início ao incêndio - show pirotécnico. As tragédias decorrentes após o início do fogo tem seu desenvolvimento em sucessivas falhas nas condições e instalações de segurança. De alguma maneira, todos estavam a observar algumas 


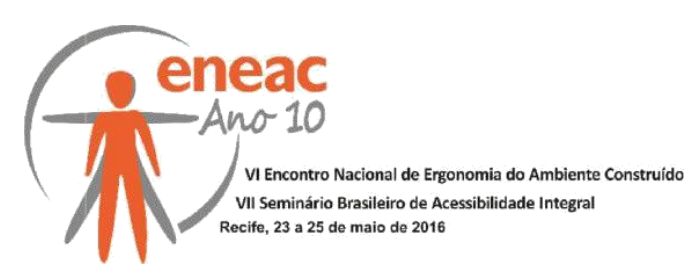

normativas de segurança, principalmente no que se refere às rotas de fuga. Conclui-se então que isto não foi suficiente para evitar mortes. Por esta razão, a pesquisa apresenta como principal objetivo, avaliar a percepção dos usuários, referente a sinalização de emergência e segurança do interior do ambiente.

Figura 2 e 3: portas internas e tentativa de abertura de vãos externos

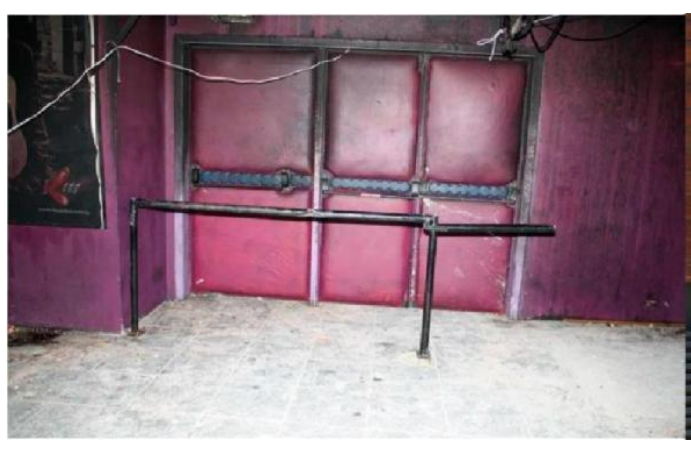

Fonte: Google Imagens

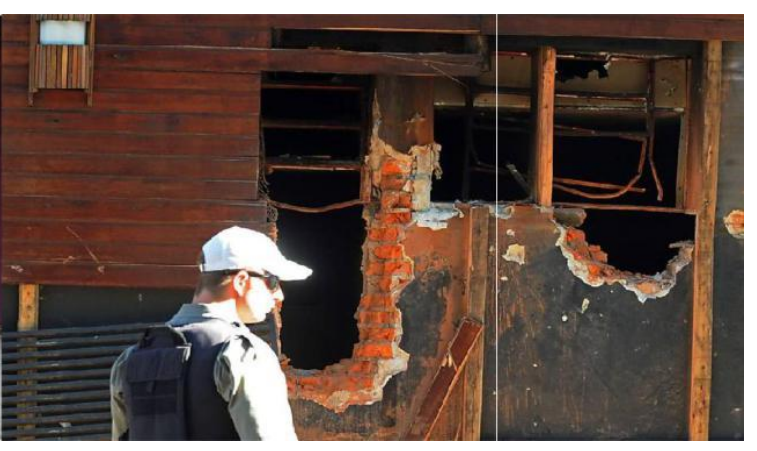

Fonte: Google Imagens

A importância de se planejar/projetar e implantar todos os elementos que proporcionam conforto e segurança aos usuários dos ambientes pode ser facilmente constatado no acidente do dia 31 dezembro 2015, em um hotel de Dubai, nos Emirados Árabes. O fato é que o fogo teve início no $20^{\circ}$ andar do edifício com 63 andares, resultando num saldo de 14 pessoas com ferimentos leves, decorrentes da operação para evacuação do prédio.

Figura 4 e 5: incêndio em hotel de Dubai.

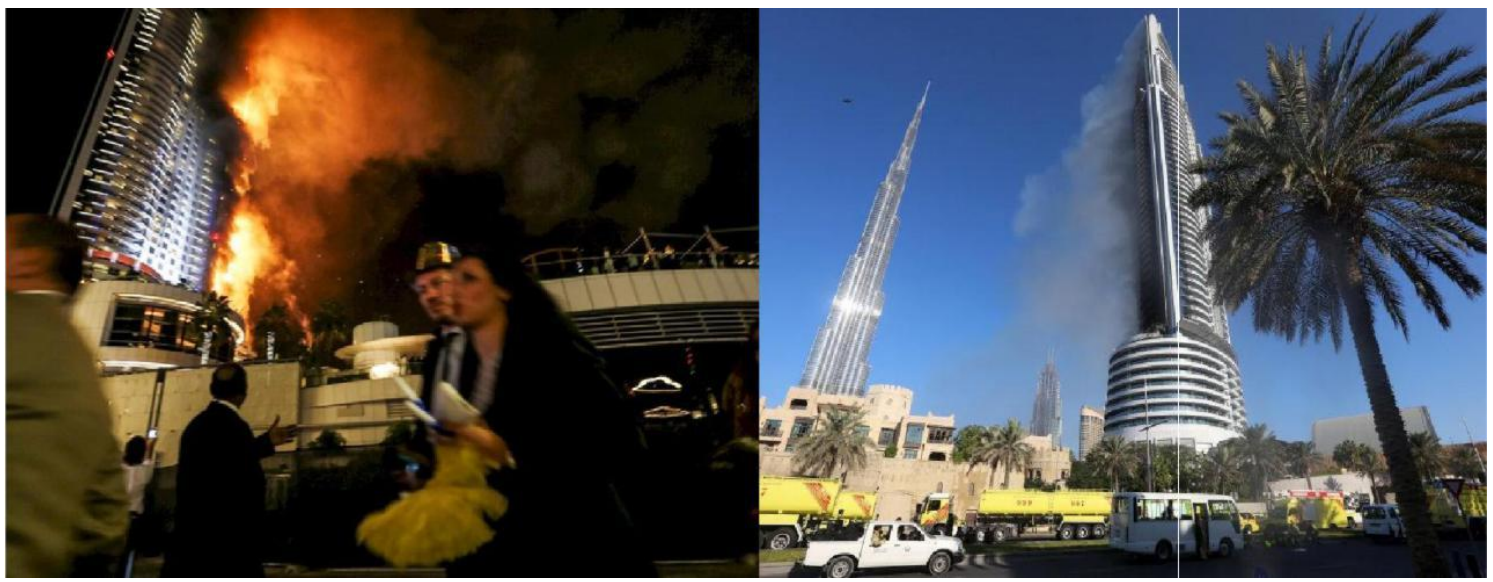

Fonte: Google Imagens

Fonte: Google Imagens

Apesar da figura da cena, não foi constatado nenhuma tragédia com perda de vidas humanas. Verifica-se então a necessidade de projetar considerando todos os aspectos perceptivos do ser humano, indo além dos padrões normativos.

\section{REVISÃO BIBLIOGRÁFI CA}

Algumas abordagens de caráter técnico e científico são significativas $p$ ara a compreensão do problema, ficando esta etapa da pesquisa para os devidos registros. Estes apresentam 


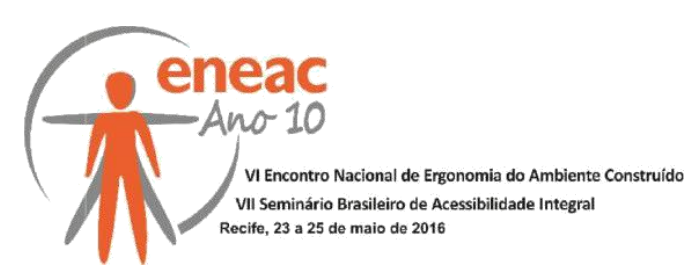

elementos que auxiliam os pesquisadores na definição da metodologia a ser trabalhada, proporcionando melhores con dições para os esclarecimentos e conclusões.

\subsection{A Legislação e a Segurança dos Ambientes}

Estão vigentes algumas normas, leis e decretos que apresentam diretrizes para regulamentação em prol da segurança dos ambientes. A nível municipal, Santa Maria apresenta a Lei Municipal no 3.301/91 intitulada de Normas de Prevenção e Proteção contra Incêndio. Desde sua publicação, já era desafiador torná-la uma lei eficaz. Textualmente, visando facilitar a determinação de medidas, apresenta a classificação e definição de imóveis conforme a NBR 9077 - Saídas de Emergências de Edifícios. A nível estadual, citamos as Normas Técnica $s$ de Prevenção contra Incêndios, que são resultantes da unificação de decretos anteriores e aprovadas no ano de 1997. Esta lei, da mesma maneira que é contemplada na legislação municipal, também remete a Associação Brasileira de Normas Técnicas - ABNT e suas respectivas Normas Regulamentadoras NRs. A nível federal, a ABNT é o Fórum Nacional de Normalização. As NRs, cujo conteúdo é de responsabilidade dos Comitês Brasileiros (ABNT/CB), dos Organismos de Normalização Setorial (ABNT/ONS) e das Comissões de Estudos Especiais Temporários (ABNT/CEET), são elaboradas por Comissões de Estudos, formadas por representantes dos setores envolvidos, delas fazendo parte produtores, consumidores e neutros (universidades, laboratórios e outros).

Relativo às questões de incêndio especificamente, delimitamos nossa pesquisa na observação da NBR 13434/ 2004 - Sinalização de Segurança contra Incêndio e Pânico: Parte 1 - Princípios de Projeto; Parte 2 - Símbolos e suas formas, dimensões e cores. No sentido de entendimento das citadas normas, são apresentadas algumas definições de sinalização que irão auxiliar para melhor justificar a contextualização das observações e abordagens:

- Sinalização de Segurança: sinalização que fornece uma mensagem de segurança, obtida por uma combinação de cor e forma geométrica, a qual é atribuída uma mensagem específica de segurança pela adição de um símbolo gráfico executado com cor de contraste.

- Sinalização de Equipamentos: sinalização que visa indicar a localização e os tipos de equipamentos de combate a incêndio e alarme disponíveis no local.

- Sinalização de orientação e salvamento: sinalização que visa indicar as rotas de saída e as ações necessárias para o seu acesso e uso adequado. 


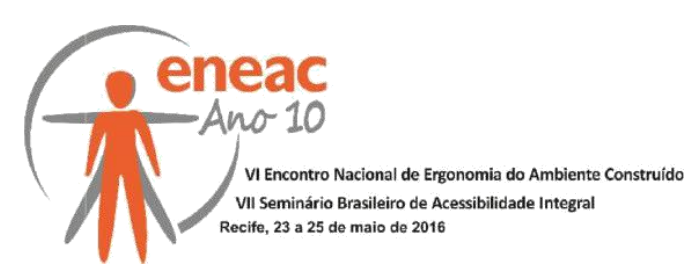

Tabela 1 - Dimensão das placas de sinalização.

\begin{tabular}{|c|c|c|c|c|c|c|c|c|c|c|c|c|c|c|}
\hline \multirow{2}{*}{ Sinal } & \multirow{2}{*}{ Forma geométrica } & \multirow{2}{*}{$\begin{array}{l}\text { Cota } \\
\mathrm{mm}\end{array}$} & \multicolumn{12}{|c|}{$\begin{array}{l}\text { Distância máxima de visibilidade } \\
\qquad \mathrm{m}\end{array}$} \\
\hline & & & 4 & 6 & 8 & 10 & 12 & 14 & 16 & 18 & 20 & 24 & 28 & 30 \\
\hline \multirow{2}{*}{$\begin{array}{l}\text { Orientação, } \\
\text { salvamento e } \\
\text { equipamentos }\end{array}$} & & L & 89 & 134 & 179 & 224 & 268 & 313 & 358 & 402 & 447 & 537 & 626 & 671 \\
\hline & $\underset{\mathrm{L}}{\mathrm{V}}$ & $\begin{array}{c}\mathrm{H} \\
(\mathrm{L}=2 \mathrm{H})\end{array}$ & 63 & 95 & 126 & 158 & 190 & 221 & 253 & 285 & 316 & 379 & 443 & 474 \\
\hline
\end{tabular}

Fonte: ABNT- NBR 13434-2 Adaptada pelo autor.

Informações complementares, em relação a altura mínima das letras em placas de sinalização em função da distância de leitura, são apresentadas na tabela 2.

Conforme se verifica na tabela 1 , a sinalização do ambiente pesquisado está enquadrada como forma de sinalização quadrada e retangular. Esta forma é utilizada para implantar símbolos de orientação, socorro, emergência e identificação de equipamentos utilizados no combate a incêndio e alarme. A cor de segurança (verde: utilizada para símbolos de orientação e socorro; vermelha: utilizada para símbolos de proibição e identificação de equipamentos de combate a incêndio e alarme), deve cobrir no mínimo $50 \%$ da área do símbolo, exceto no símbolo de proibição, onde este valor deve ser no mínimo de $35 \%$

Tabela 2 Sinalização de Orientação e Salvamento.

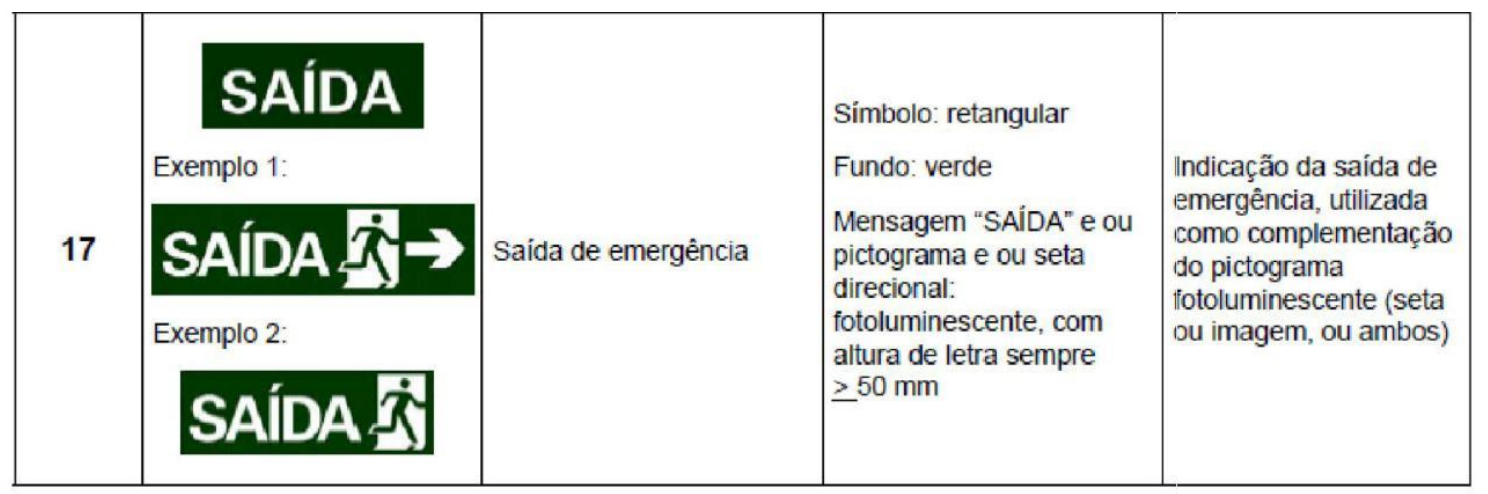

Fonte: ABNT- NBR 13434-2

Além da sinalização de orientação e salvamento, a referida norma também apresenta a padronização de formas, dimensões e cores da sinalização complementar. Esta sinalização é utilizada para indicação continuada de rotas de fuga, indicação de obstáculos e indicação das condições de uso de portas corta-fogo. 


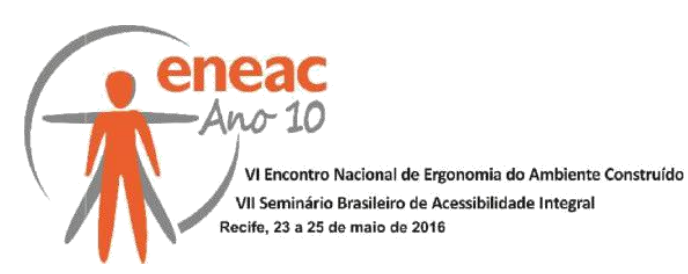

Tabela 3 Sinalização complementar: indicação continuada de rota de fuga.

\begin{tabular}{|l|l|l|l|}
\hline Código & \multicolumn{1}{|c|}{ Símbolo } & \multicolumn{1}{c|}{ Significado } & \multicolumn{1}{c|}{ Forma e cor } \\
\hline 28 & & Sentido da rota de saída & $\begin{array}{l}\text { Simbolo: retangular } \\
\text { Fundo: verde } \\
\text { Pictograma: } \\
\text { fotoluminescente }\end{array}$ \\
\hline
\end{tabular}

Fonte: ABNT- NBR 13434-2

Tabela 4 Sinalização complementar: indicação de obstáculo.

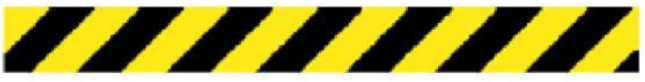

B1

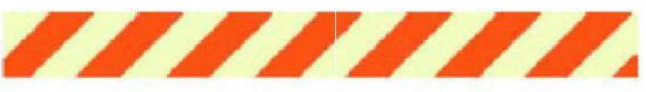

\section{A2}

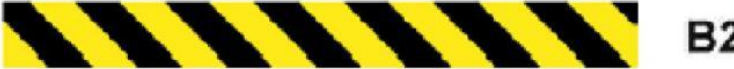

Fonte: ABNT- NBR 13434-2

Em decorrência da tragédia a Boate Kiss, houve um clamor popular em nível nacional, no sentido de que as autoridades políticas pudessem promover alterações na legislação, aumentando a segurança contra incêndio nos ambientes. Assim, o estado do Rio Grande do Sul apresentou a sociedade gaúcha o decreto no 51.803, de 10 de setembro de 2014 em que regulamenta a Lei Complementar № 14.376/13 (Lei Kiss), que estabelece normas de segurança, prevenção e proteção contra incêndio nas edificações e áreas de risco de incêndio.

Esta nova lei não altera as condições da formatação e instalação da sinalização prevista nas normas da ABNT. Estabelece algumas regras para procedimentos e informações ao público do local, bem como o incremento de novos equipamentos e instalações, em função do número de pessoas nos estabelecimentos. Ficou assim determinado:

Local de reunião de público - Casas Noturnas - Grupo F.

Notas Gerais: (letras a e b são itens não relacionados ao tema da pesquisa)

c) nos locais de concentração de público, é obrigatória, antes do início de cada evento, a explanação ao público da localização das saídas de emergência, bem como dos sistemas de segurança contra incêndio existentes no local.

d) Iluminação de balizamento das rotas de saída (luz-piloto permanente) e para edificações sem ventilação natural (janela s) exige-se controle de fumaça.

Art. 28. Deverá ser afixado em local visível, nos acessos da edificação/área de risco de incêndio da divisão do grupo "F", placa (s) de material (is) resistente (s), informando a lotação máxima no local.

Apresentado o contexto de normativas legais pertinentes a temática da pesquisa, podemos constatar a responsabilidade dos profissionais projetistas em observar os condicionantes de projetos no que se refere a segurança dos ambientes construídos. Além das questões abordadas, é também de significativa importância compreender a lógica da percepção do 


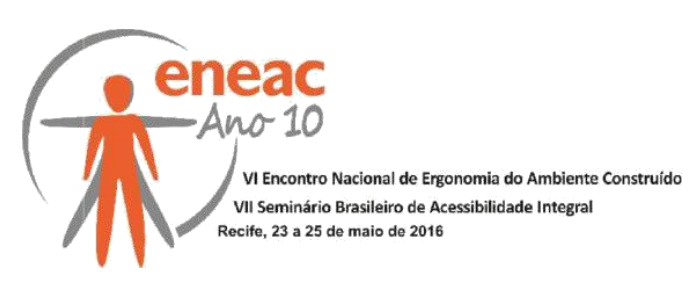

espaço que o indivíduo ocupa. Neste sentido, apresentamos uma breve abordagem dos conceitos e registros que graficamente possam trazer elementos importantes para as análises dos resultados.

\subsubsection{A Percepção do Espaço}

Segundo Cremonini (1998), $\mathrm{n}$ a década de 50, alguns autores afirmavam que a maioria das teorias perceptivas davam ênfase a um aspecto interativo, argumentando a relação entre o sensório, o cognitivo e o conotativo de modo que as propriedades perceptivas de um objeto estão em função da maneira através da qual os estímulos que vem d o objeto afetam o estado do organismo.

As teorias perceptivas indiretas têm como pressuposto a noção de que os sentidos são providos de descrições simples do mundo, ou seja, os estímulos que vêm do meio ambiente não fornecem informações seguras sobre os acontecimentos e os objetos. De outra forma, a percepção é bastante rica e o sistema sensorial exerce um importante papel ao processar as informações, através de operações cognitivas, que passam a ter um real significado para o indivíduo (SANTOS, 1986).

"Espaço" é um termo abstrato para um conjunto complexo de ideias. Pessoas de diferentes culturas divergem quanto a forma de separar seu mundo, de atribuir valo res às suas partes e de medi-las. As maneiras de dividir o espaço variam enormemente e $\mathrm{m}$ complexidade e sofisticação, assim como as técnicas de avaliação de tamanho e distância. Contudo, existem certas semelhanças culturais comuns, e elas repousam basicamente no fato de que o homem é a medida de todas as coisas. Em outras palavras, os princípios fundamentais da organização espacial baseiam-se nos resultados da experiência íntima d o homem com seu corpo e com outras pessoas, organizando o espaço a fim de conformálo as suas necessidades biológicas e relações sociais (TUAN, 1980).

\subsubsection{Representações Espaciais}

A maneira de expressar a nossa percepção é por meio do que Richard ( 1990) denomina de "representação". Este termo está relacionado às construções circunstanciais, feitas num contexto particular e com fins específicos. O que diferencia "representação" de "conhecimento", é que este último está relacionado às construções estáveis, permanentes e não inteiramente dependentes da tarefa de realizar. Estas distinções são também definidas como um termo único - "representações" - qualificando como: representações tipos (chamadas conhecimento) e representações ocorrentes (chamadas representações), ou estruturas permanentes e circunstanciais. Diante de uma estrutura cognitiva de representação, alguns autores como Sternberg (2000) relatam que a maioria das pesquisas sobre a imaginação visual e a representação mental do conhecimento visual, como por exemplo, objetos ou ambiente s, não são visíveis aos olhos.

\subsubsection{Os Mapas Mentais}

Segundo Richard (1990), Mapa Mental significa entender como se passa da representação de um trajeto conhecido ou d e um trajeto descrito verbalmente "routemap" a uma 


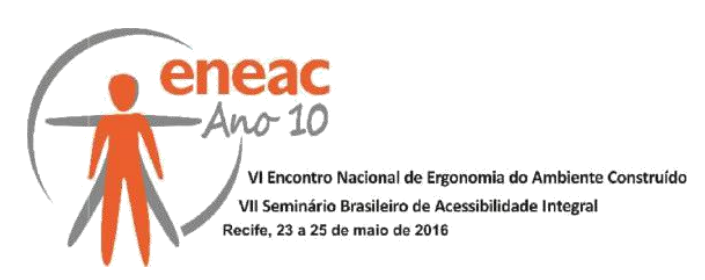

Representação espacial onde os elementos são representados não somente por suas posições relativas, mas também por suas posições absolutas e suas distâncias "surveymap".

Cremonini (1998), apresenta a definição de Mapa Mental como sendo as imagens mentais, que as pessoas deduzem do seu meio físico e que afetam seu comportamento. São transformações psicológicas as quais levam os indivíduos a lembrar do seu meio ambiente espacial e que são produzidas por suas preferências mais significativas, sejam elas afetivas e/ou simbólicas. Desta maneira, pode-se concluir que o homem armazena na memória toda a informação proveniente dos ambientes por ele observados e que são transmitidas pelos canais sensoriais. $O$ armazenamento ocorre em forma de imagens e estas por sua vez são incorporadas de ideias. Por meio de esquemas imaginativos, há uma confrontação da realidade com as imagens para avaliação dos ambientes. Segundo Cremonini, os esquemas são construídos através do tempo e estão relacionados com a experiência do indivíduo e variáveis como cultura, sistemas de atividades, posicionamentos e localização. Assim sendo, os Mapas Mentais são representações espaciais das imagens mentais, resgatadas da memória de experiências anteriores, internacionalizadas pelos canais sensoriais do homem através da percepção. Logo, é considerada uma ferramenta capaz de fornecer dados que auxiliem na compreensão da percepção do espaço físico pelo usuário.

Lynch (1980) foi o primeiro a usar a técnica dos Mapas Mentais, com o qual analisou os desenhos feitos por habitantes das cidades americanas de Los Angeles, Boston e Jersey. Objetivou revelar a identidade de cada cidade, diferenciando-as. Interpretou a estrutura e a integração da relação espacial do ambiente e o sentido que tem para o seu observador. Um dos aspectos considerados mais importantes é a representação através da estrutura cognitiva, em que o indivíduo representa os componentes do espaço exterior do habitat, e que muitas vezes é avalia do segundo critérios estéticos, como também representa 0 aspecto interior, que avalia segundo critérios de habitabilidade.

\section{METODOLOGIA}

A utilização de um método, segundo Gil (1999, p.33) tem por objetivo proporcionar ao investigador os meios técnicos para garantir a objetividade e a precisão no estudo dos fatos sociais. Mais especificamente visam fornecer a orientação necessária à realização da pesquisa social, sobretudo no referente à obtenção, processamento e validação dos dados pertinentes à problemática que está sendo investigada.

Podem ser identificados vários métodos desta natureza nas ciências sociais. Nem sempre um método é adotado rigorosamente ou exclusivamente numa investigação. Com frequência, dois ou mais métodos são combinados, isto porque nem sempre um único é suficiente para orientar todos os procedimentos a serem desenvolvidos ao longo da investigação.

O método utilizado neste estudo é o experimental, que consiste essencialmente em submeter os elementos de estudo à influência de certas variáveis, em condições controladas e conhecidas pelo investigador, para observar os resultados que a variável produz. Por sua contribuição nos conhecimentos obtidos nos últimos três séculos, pode ser considerado como o método, por excelência, o das ciências naturais. 


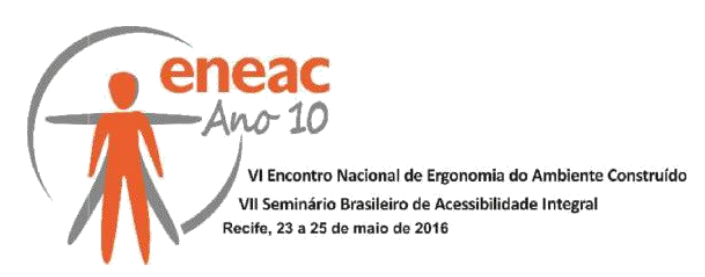

Em relação ao objetivo proposto, a pesquisa é classificada como exploratória, onde a principal finalidade é o aprimoramento de ideias ou a descoberta de intuições. Seu planejamento é, portanto, bastante flexível, possibilitando a consideração dos mais variados aspectos relativos ao fato estudado. No caso específico desta pesquisa, serão aplicadas entrevistas com pessoas que estavam no interior da Boate Kiss no dia da tragédia. Assim sendo, possibilitará sua análise segundo critérios de um estudo de caso, favorecendo o esclarecimento para melhor compreensão do "problema" e descrevendo os resultados para a análise, mais na condição de hipótese do que de conclusões (GIL, 2002).

Em relação a natureza, a pesquisa é classificada como aplicada, uma vez que objetivamente deverá fornecer elementos $p$ ara auxiliar os profissionais nas reflexões e discussões dos comitês técnicos que debatem o problema. Segundo Silva \& Menezes (2000, p.20) a pesquisa aplicada, além de envolver verdades e interesses localizados, "objetiva gerar conhecimento para aplicação prática em soluções de problemas específicos”.

A preparação para a coleta de dados é uma atividade complexa e difícil. Se não for realizada corretamente, pode por em risco tudo o que foi planejado inicialmente ao definir o problema da pesquisa e a configuração do projeto. Em função principalmente de algumas variáveis envolvidas, esta pesquisa exigiu dos pesquisadores, muita competência na sua preparação.

\subsection{O ambiente e a Oportunidade da Ação Proposta}

Diante da tragédia e na condição de professor do curso de Desenho Industrial da UFSM, arquiteto e engenheiro de segurança, não restou outra condição senão explorar os fatos para de alguma forma poder contribuir para a diminuição das possibilidades de outras tragédias. Neste contexto foi utilizada uma metodologia já estruturada por Brondani (2006) e aplicada com profissional da neurociência e acadêmicos que sobreviveram a tragédia. A preparação para a coleta de dados foi desenvolvida em três etapas:

a) Primeira etapa: busca por informações e documentação local - Com o apoio da Polícia Civil do RS, tivemos acesso aos projetos arquitetônicos que constavam da documentação do inquérito policial. Junto aos órgãos da administração pública do município, foram coletados as normas e regulamentos de prevenção de incêndio. Demais documentos e bibliografias foram acessados em sites e bibliotecas.

b) Segunda etapa: junto a marcenaria do curso de Desenho Industrial da UFSM, foi então materializada a planta baixa da Boate Kiss. Caracterizou-se como uma maquete de planta esquemática, produzida com o corte de chapa de MDF10mm, definindo os acessos, ambientes e paredes divisórias. Esta pro posta visa facilitar o registro do percurso do pesquisado quando da sua saída do interior do ambiente da boate. A montagem e preparação do teste consiste inicialmente em posicionar sobre uma mesa uma placa de poliestireno. Esta, então, será a superfície para colocação do papel onde está graficada a planta baixa. Sobre este, é posicionada a maquete esquemática, coincidente com a planta baixa. Após estabilizada, estará pronta para a graficação do percurso.

c) Terceira etapa: elaboração dos Mapas Mentais (MMs) - foi aplicado o "teste piloto" com um dos sobreviventes da tragédia. Este foi informado de que não haveria 


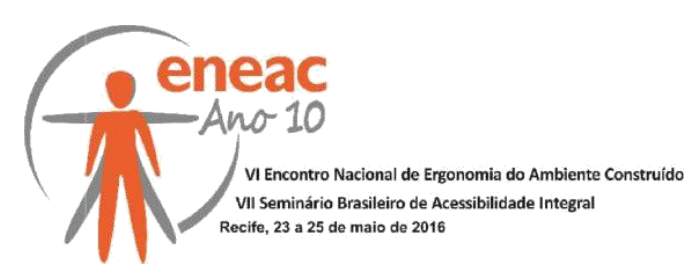

tempo cronometrado para a realização da tarefa, usaria o tempo que julgasse necessário. Disponibilizando de lápis, caneta e borracha, foi então traçado o percurso, denominado de MM. Inicialmente é dada explicação sobre a maquete, identificando os ambientes e os acessos, fazendo com que o pesquisa se situe no local, como no dia da tragédia. O pesquisador acompanha durante todo o tempo do desenvolvimento da pesquisa, identificando e assinalando o início e o término do percurso. Na busca por mais informações, antes da representação dos MMs, foi aplicada uma entrevista com o pesquisado, no sentido de auxiliar nas futuras análises da percepção. Modelo de entrevista proposto:

1) Nome:

2) Sexo: ( )M ( $) \mathrm{F}$

3) Idade quando do dia da tragédia:

4) Já havia frequentado a boate antes da tragédia: ( )Sim ( )Não Quantas vezes:

Tempo para explicar a implantação da maquete esquemática;

Com lápis e caneta, traçar o percurso de saída que você lembra ter feito no local durante o incêndio;

5) Lembra de alguma sinalização indicativa de saída de emergência que auxiliou na sua saída:

\section{SAÍDA SAÍDA}
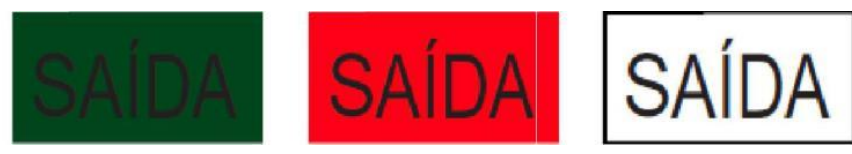

( ) Sim ( )Não

6) Onde morava quando do dia da tragédia: ( )Casa ( )Apartamento.

7) No local em que você morava, existia alguma sinalização indicativa de saída de emergência: ( )Sim ( )Não (em caso afirmativo, apresentar propostas de sinalização sugeridas para a escolha do ator pesquisado):

8) Onde mora hoje: ( )Casa ( )Apartamento.

9) No local em que você mora, existe alguma sinalização indicativa de saída de emergência: ( )Sim ( )Não (em caso afirmativo, apresentar propostas de sinalização sugeridas para a escolha do ator pesquisado):

10) Esteve internado em função do incêndio da Boate Kiss: ( )Sim( )Não

11) Esteve internado no hospital sob ventilação mecânica: ( )Sim ( )Não

12) Fez queimadura de pele: ( )Sim ( )Não

13) Fez ou faz tratamento psiquiátrico e/ou psicológico: ( )Sim ( )Não

14) Faz uso de algum tipo de medicação: ( )Sim ( )Não

Legenda utilizada para demarcações no traçado da rota de fuga:

Letra "l": início do percurso;

Letra "F": final do percurso;

Linha Contínua (—): percurso livre;

Linha Tracejada ( - - - --): percurso congestionado. 


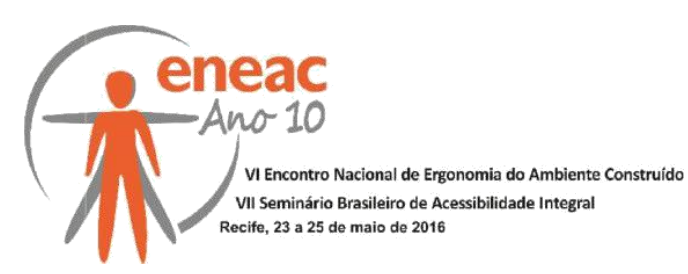

No desenvolvimento da pesquisa, a cada novo ator pesquisado, será retirada a maquete esquemática e substituído o papel com o MM. Todos os registros gráficos serão identificados individualmente e arquivados para as análises.

Está previsto trabalhar com um número mínimo de vinte atores. Para uma análise estatística, este número é aceito para avaliar uma pesquisa exploratória. Os resultados obtidos poderão direcionar para outras pesquisas, tendo em vista a caracterização de algumas variáveis.

\section{RESULTADO DA ANÁLISE E INTERPRETAÇÃO DO MAPA MENTA L}

A elaboração do MM representado com o trajeto do percurso do ator favoreceu a análise principalmente durante 0 "teste piloto". Evidenciou a necessidade de ser identificado o trecho de maior dificuldade $\mathrm{n}$ o deslocamento do percurso. Esta condição possibilitou fazer novos questionamentos, que na sua plena aplicação com o público a ser pesquisado, trará elementos que consideramos importantes no resultado das variáveis investigadas. Neste contexto, verificado, a neurociência poderá fazer analogias com as representações dos MMs entre os atores que foram submetidos a ventilação mecânica durante o período de internação e os demais que não necessitaram destes recursos para sua sobrevivência.

Figura 6: Elaboração do "projeto piloto" por ator pesquisado.

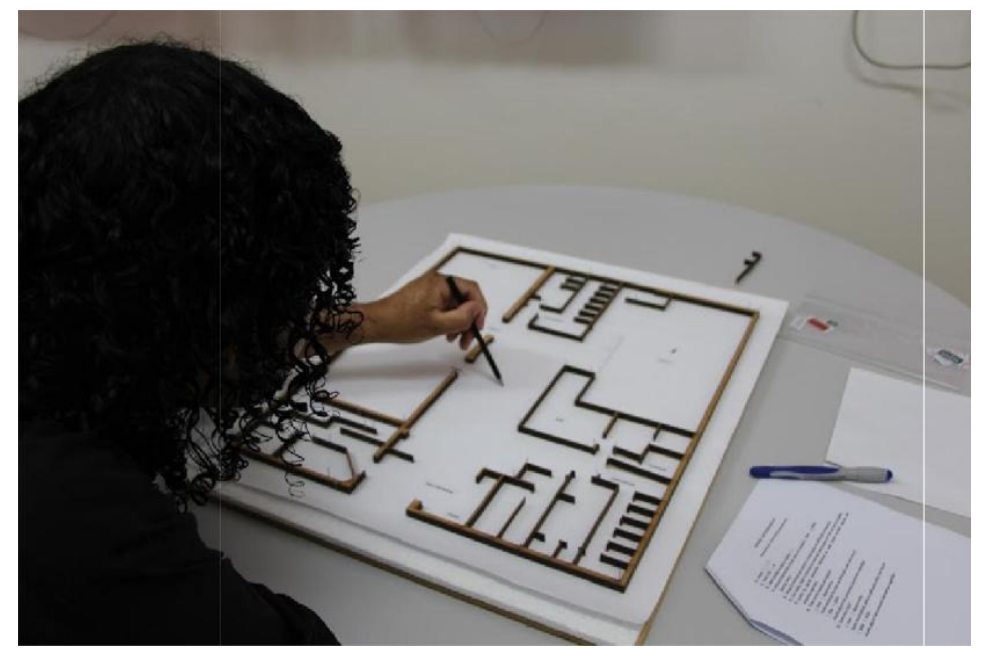

\section{CONCLUSÃO}

\section{Respondendo aos Pressupostos da Pesquisa}

Com novos estudos e métodos avaliativos realizados por equipes interdisciplinares, podemos ampliar nosso campo de conhecimento e com isso auxiliar com a segurança nas prescrições normativas. Pouco se conhece sobre os métodos utilizados para compreensão e definição dos elementos técnicos contemplados na legislação que trata sobre segurança contra incêndio nas edificações. 


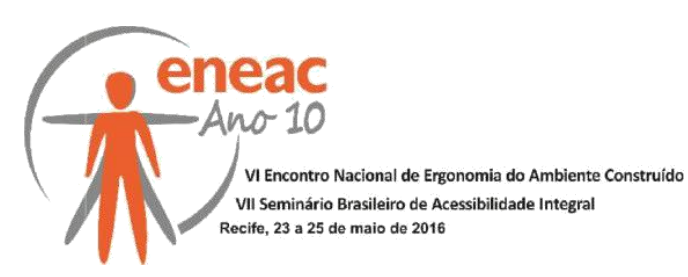

Como metodologia já utilizada em outros estudos para a avaliação da percepção ambiental, estamos convictos que trará resultados e que possam responder o porquê de tantas mortes em situações similares e assim agregar mais segurança nos ambientes.

Respondendo aos objetivos da pesquisa, a amostra do "teste piloto" aperfeiçoado, demonstra que o MM é uma ferramenta aprovada para a continuidade da pesquisa. Ficou evidenciado que $o$ ator pesquisado entendeu a proposta e esteve muito a vontade durante a sua representação. Em nenhum momento sentiu qualquer constrangimento ou desconforto que pudesse comprometer o seu desenvolvimento. Diante do exposto, percebe-se a importância da interdisciplinaridade dos pesquisadores, fato que facilitou a identificação das variáveis, e por consequência, seu tratamento futuro.

\section{REFERÊNCIAS BIBLIOG RÁFICAS}

ASSOCIAÇÃO BRASILEIRA DE NORMAS TÉCNICAS. NBR 13434: Sinalização de segurança contra incêndio e pânico. Parte 2: Símbolos e suas formas, dimensões e cores. Rio de Janeiro, 2004.

BRONDANI, Sergio A. A percepção da luz artificial no interior de ambientes edificados. 2006. Tese (Doutorado em Engenharia de Produção) - Universidade Federal de Santa Catarina, Florianópolis, 2006.

CREMONINI, R. S. C. A percepção do espaço físico pelo usuário: uma compreensão através dos mapas mentais. 1998. 156p. Dissertação (Mestrado em Engenharia de Produção) - Universidade Federal de Santa Catarina, Florianópolis, 1998.

DECRETO № 51.803: Estabelece normas sobre segurança, prevenção e proteção contra incêndio nas edificações e áreas de risco de incêndio no Estado do Rio Grande do Sul. Porto Alegre, 2014.

GIL, A. C. Como elaborar projetos de pesquisa. 4. Ed. São Paulo: Atlas , 2002. 175p.

Métodos e Técnicas de Pesquisa Social. 5. Ed. São Paulo: Atla s, 1999.

LYNCH, K. A Imagem da Cidade. Tradução Jefferson Luiz Camargo. São Paulo: Martins Fontes, 1980. 227p.

RICHARD, J. Traité de psychologiacognitive. Dumod, Paris, 1990.

SANTOS, M. Pensando o espaço do homem. São Paulo: Hucitec, 1986.

SILVA, E. L.; MENEZES, E. M. Metodologia da Pesquisa e Elaboração de Dissertação. Florianópolis: LED/UFSC. 20 00. 118p.

STERnBERG, R. J. Psicologia cognitive. Porto Alegre: Artes Médicas Sul, 2000.

TUAN, yi-fu. Topofilia: um estudo da percepção, atitudes e valores do meio ambiente. Tradução Lívia de Oliveira. São Paulo: Difel Difusão, 1980. 288p. 